\title{
ARP, A Peptide Derived from the Stress-Associated Acetylcholinesterase Variant, Has Hematopoietic Growth Promoting Activities
}

\author{
Dan Grisaru, ${ }^{1,4}$ Varda Deutsch, ${ }^{2}$ Michael Shapira, ${ }^{1}$ Marjorie Pick, ${ }^{2}$ Meira Sternfeld, ${ }^{1}$ \\ Naomi Melamed-Book, ${ }^{1}$ Daniela Kaufer, ${ }^{1}$ Nilly Galyam, ${ }^{1}$ Michael J. Gait, ${ }^{3}$ David Owen, ${ }^{3}$ \\ Joseph B. Lessing, ${ }^{4}$ Amiram Eldor, ${ }^{2}$ and Hermona Soreq ${ }^{1,5}$ \\ ${ }^{1}$ Department of Biological Chemistry, Institute of Life Sciences, Hebrew University of Jerusalem, Israel \\ ${ }^{2}$ Department of Hematology, Tel-Aviv Sourasky Medical Center, Sackler Faculty of Medicine, Tel Aviv \\ University, Israel \\ ${ }^{3}$ Medical Research Council, Laboratory of Molecular Biology, Hills Road, Cambridge, UK \\ ${ }^{4}$ Department of Obstetrics-Gynecology, Sourasky Medical Center, Sackler Faculty of Medicine, \\ Tel Aviv University, Israel \\ Accepted October 2, 2000.
}

\begin{abstract}
Background: Psychological stress induces rapid and longlasting changes in blood cell composition, implying the existence of stress-induced factors that modulate hematopoiesis. Here we report the involvement of the stressassociated "readthrough" acetylcholinesterase (AChE-R) variant, and its 26 amino acid C-terminal domain (ARP) in hematopoietic stress responses.

Materials and Methods: We studied the effects of stress, cortisol, antisense oligonucleotides to AChE, and synthetic ARP on peripheral blood cell composition and clonogenic progenitor status in mice under normal and stress conditions, and on purified CD $34^{1}$ cells of human origin. We employed in situ hybridization and immunocytochemical staining to monitor gene expression, and 5-bromo-2-deoxyuridine (BrdU), primary liquid cultures, and clonogenic progenitor assays to correlate AChE-R and
\end{abstract}

ARP with proliferation and differentiation of hematopoietic progenitors.

Results: We identified two putative glucocorticoid response elements in the human ACHE gene encoding AChE. In human $\mathrm{CD}_{3} 4^{1}$ hematopoietic progenitor cells, cortisol elevated AChE-R mRNA levels and promoted hematopoietic expansion. In mice, a small peptide crossreacting with anti-ARP antiserum appeared in serum following forced swim stress. Ex vivo, ARP was more effective than cortisol and equally as effective as stem cell factor in promoting expansion and differentiation of early hematopoietic progenitor cells into myeloid and megakaryocyte lineages.

Conclusions: Our findings attribute a role to AChE-R and ARP in hematopoietic homeostasis following stress, and suggest the use of ARP in clinical settings where ex vivo expansion of progenitor cells is required.

\section{Introduction}

Stress insults are associated with rapid and significant changes in blood cell composition (1). For example, following massive blood loss or after surgery, the hematopoietic system responds within hours with an elevation of the white blood cell (WBC) and platelet counts (2). However, the molecular mechanisms regulating this adjustment are not yet fully understood. Glucocorticoid hormones play a leading role in the adaptive reaction of the bone marrow to stress (3), inducing absolute increases in all

Address correspondence and reprint requests to: Hermona Soreq Department of Biological Chemistry, Institute of Life Sciences, Hebrew University of Jerusalem, Israel; fax: 972-2-6520258; e-mail: soreq@shum.huji.ac.il

The first two authors contributed equally to this investigation. hematopoietic lineages, especially myeloid cells (4), and release of WBC to the periphery (5). Glucocorticoids evoke cascades culminating in the proliferation, differentiation, and apoptotic events characteristic of each of the hematopoietic cell lineages [for review see (6)]. In addition, glucocorticoid hormones mediate changes in the levels of hematopoietic growth factors that control the proliferation of hematopoietic stem cells $(7,8)$.

Hematopoietic stem cells are pluripotent in that they give rise to all blood cell lineages. During ontogeny, they migrate from the fetal liver to permanently reside in the bone marrow where they provide a life-long, self-renewing source of blood cells (9). Under normal conditions, the vast majority of these stem cells are nondividing. However, under conditions of development or stress 
they can undergo clonal expansion and self-renewal (10). A large number of early-acting cytokines and growth factors, such as stem cell factor (SCF), thrombopoietin (TPO), and FLT-3 ligand, are thought to mediate the proliferative capacity of hematopoietic stem cells, through specific receptors-c-kit, c-mpl, and flt3/flk-2, respectively (11-14). Alone, their capacity to stimulate proliferation is limited. For example, SCF can maintain survival of stem cells for a few days in vitro, but not self-renewal (15). In combination, however, these growth factors acquire a potent costimulatory effect $(16-18)$. The early phase of adaptation of the hematopoietic system to stress (first $24 \mathrm{hr}$ ) requires coordinator(s), such as leuenkephalin (19), which modulate the effects of growth factors on stem cells. However, leuenkephalin is present in the circulation only immediately following the stress insult, whereas the modulation of hematopoiesis continues long after. Therefore, additional long-acting modulators remain to be identified.

An intriguing, previously unpredicted candidate for a role(s) in hematopoietic stress responses is the acetylcholine hydrolyzing enzyme, acetylcholinesterase (AChE). In addition to its wellknown localization at sites of cholinergic neurotransmission, AChE is also expressed in multiple embryonic and tumor tissues $(20,21)$, including those producing blood and bone cells $(22,23)$, shown to share common progenitors (24). In hematopoietic cells, AChE has been proposed to exert a growth regulatory role $(25,26)$. In humans, AChE gene expression was demonstrated in early $2 \mathrm{~N}$ megakaryocytes and observed to decrease with cellular development and differentiation (22). Alternative splicing gives rise to three distinct $\mathrm{AChE}$ variants: "synaptic" (AChE-S), "erythrocytic" (AChE-E), and "readthrough" (AChE-R) (20,23). AChE-R derives from a normally rare mRNA species in which intron I4 is not spliced out, but retained in the mature AChE-R mRNA transcript (20) to give rise to an AChE variant with unique properties (27). Until recently, it was not possible to assign hematopoietic activities to any specific AChE variant. In mouse brain, however, AChE-R is significantly and persistently overexpressed following trauma (28). In the brain, overexpressed AChE-R was implicated in stress-induced changes in neuronal structure and function (28-30). Together, these observations suggested a possible role for AChE-R in hematopoietic stress responses.

Here, we demonstrate induction of AChE-R mRNA in human CD $34^{1}$ hematopoietic progenitor cells by cortisol, and associate elevated AChE-R with enhanced hematopoietic activity in stressed mice. We trace the in vivo hematopoietic activities of AChE-R to a small, stress-induced peptide apparently cleaved from the C-terminus, and demonstrate potent in vivo and ex vivo activities for ARP, a synthetic 26-amino acid peptide based on the unique AChE-R C-terminal sequence. ARP was more effective than cortisol and equally as effective as stem cell factor in promoting expansion and differentiation of bone marrow cells into myeloid and megakaryocyte lineages. Our findings indicate that AChE-R participates in hematopoietic homeostasis following stress, and suggest the use of ARP to facilitate ex vivo expansion of hematopoietic stem cells.

\section{Materials and Methods}

Cell Source

Human umbilical cord blood (UCB) was collected after normal deliveries following informed consent of the parents and with the approval of the Tel Aviv Medical Center Ethics Committee according to the regulations of the Helsinki accords, as previously described (31). Volumes of 70-100 mL of UCB samples were collected in heparinized $(20 \mathrm{IU} / \mathrm{mL})$ tubes or bags and processed within $8 \mathrm{hr}$ of collection.

\section{Isolation of Human UCB Hematopoietic Progenitors}

UCB samples were spun at $3500 \mathrm{rpm}$ for $20 \mathrm{~min}$ for initial separation of autologous plasma. The volume of plasma that was removed from the entire UCB sample (approximately one-third) was replaced with SFM (CellGenix Technologie Transfer GmbH, Freiburg, Germany). The plasma was recentrifuged at $5000 \mathrm{rpm}$ for $10 \mathrm{~min}$, filtered through a $0.2-\mu \mathrm{m}$ filter (Corning Glass Works, Corning, NY) and frozen in aliquots at $2708 \mathrm{C}(32)$. CD $34^{1}$ progenitor cells were isolated from UCB to . $85 \%$ purity as previously described $(33,34)$. Briefly, the UCB sample was diluted $1: 1(\mathrm{v} / \mathrm{v})$ in Iscove's modified Dulbecco medium (IMDM, Biological Industries, Beit Haemek, Israel), the red cell bulk was removed on a $3 \%$ gelatin density gradient (Difco, Detroit, Mich) and progenitor-enriched nucleated cells were isolated on Ficoll-Hypaque gradients $(, 1.077 \mathrm{~g} / \mathrm{ml}$; Pharmacia, Uppsala, Sweden). Adherent cells were subsequently depleted by incubation for $90 \mathrm{~min}$ in a tissue culture flask at $378 \mathrm{C}, 5 \% \mathrm{CO}_{2}$. The nonadherent cells were layered over fetal calf serum (FCS) (Beit Haemek, Israel) and centrifuged at 500-x g for 10 minutes to remove the platelets. All cell counts were determined by hemocytometer counting or Coulter STKS analysis (Coulter, Hialeah, Fla). The CD $34^{1}$ cells were isolated using CD $34^{1}$-specific immune magnetic beads followed by treatment with detachabead (CD34 progenitor cell selection system, Dynal, Norway). CD $34^{1}$ cell analysis was performed by flow cytometry (Becton Dickinson Immunocytochemistry System Inc., San Jose, Calif), using fluorochrome conjugated monoclonal antibodies CD34-PE (Becton Dickinson) and CD45-FITC (Dako, Glostrup, Denmark). MayGrünwald-Giemsa staining revealed stem cell morphology. 


\section{Cell Proliferation}

Cells were grown in microwell plates for 16-36 hr in IMDM supplemented with $10 \%$ autologous plasma and GM-CSF (10 ng/mL) (R\&D Systems, Minneapolis, Minn) with or without ARP (50 $\mathrm{ng} / \mathrm{mL})$ and AS 1 (20 pM). Cell proliferation was assessed by incorporation of 5-bromo-2-deoxyuridine (BrdU) as previously described (23).Viable cells were counted by trypan blue dye exclusion. Cortisol sodium succinate (Abic Ltd., Netania, Israel) and antisense oligonucleotides were added for the noted periods.

\section{Expansion of Human UCB Progenitors in Liquid Cultures}

CD $34^{1}$ progenitors were cultured in IMDM supplemented with $10 \%$ autologous plasma and a cocktail of early-acting human recombinant cytokines, which included interleukin 3 (IL-3, $5 \mathrm{ng} / \mathrm{mL}$, Immunex, Seattle, Wash), interleukin 6 (IL-6, $50 \mathrm{ng} / \mathrm{mL}$, R\&D Systems), TPO (10 ng/mL, R\&D Systems), SCF (10 ng/ $\mathrm{mL}, \mathrm{R} \& \mathrm{D}$ Systems), FLT-3 ligand (FL, $50 \mathrm{ng} / \mathrm{mL}$, R\&D Systems), for up to 28 days as described by Piacibello et al (35). Liquid cultures were initiated in 96 flat bottom microwell plates (Nunc) at a concentration of $10^{4}$ cells/well in a volume of $200 \mu \mathrm{l}$ or in 24-well tissue culture plates at a concentration of 1-2 $310^{5} \mathrm{cell} / \mathrm{well}$ in a volume of $1 \mathrm{~mL}$. Single cytokines or their combinations were added immediately after seeding. Proliferating cells were demidepleted and fresh cytokines were added every 4-7 days depending on the cell density in each culture. Synthetic ARP was added to 2 nM where noted. Cells were incubated for up to 28 days at $378 \mathrm{C}$ in $5 \% \mathrm{CO}_{2}$ in fully humidified atmosphere. Viability was assessed by trypan blue dye exclusion.

\section{In Situ Hybridization}

In situ hybridization procedures were performed on cultured cells as detailed elsewhere $(23,28)$. Cultured cells were spun down at $3003 \mathrm{~g}$ and fixed to collagen-coated coverslips on the bottom of the culture well using $4 \%$ paraformaldehyde. 50-mer, 59 biotinylated, fully 29O-methylated AChE cRNA probes complementary to 39-alternative human ACHE exons were purchased from Microsynth GmbH (Switzerland). Confocal scans of the culturederived cells were obtained using a MRC-1024 BioRad confocal microscope. A projection was built from each cell and specific criteria were set for size and intensity of the Fast Red fluorescence. ImagePro image analysis software (Media Cybernetics, Silver Spring, Md) was used to analyze the signal obtained.

\section{Mouse Blood and Bone Marrow}

Blood was collected by cardiac puncture just prior to animal sacrifice. The syringes were flushed with heparin prior to the procedure and blood was collected in pediatric K/EDTA blood counting tubes
(Becton-Dickinson). Complete blood counts were performed using a Coulter AcT diff counter (BeckmanCoulter Inc., Fullerton, Calif). Bone marrow was collected from mouse femurs and smears prepared and fixed with $4 \%$ paraformaldehyde $(10 \mathrm{~min}$ at room temperature). Immuocytochemical staining was as detailed elsewhere (22) using the ABC Elite kit (Vector Labs, Burlingame, Calif) and diaminobenzidine-hydrogen peroxide (Sigma Chemical Co., $10 \mathrm{~min}$ ) with Meyer's hematoxylin for counterstaining. Confined swim stress was as detailed (28).

\section{Human AChE C-Terminal Peptides}

Peptides were synthesized on a PerSeptive Biosystems Pioneer Synthesizer on $0.1 \mathrm{mmol}$ polyethylene glycol-polystyrene resin using $\mathrm{N}$-a-Fmoc protected amino acids with the following side-chain protection: $\operatorname{Arg}(\mathrm{Pbf}), \quad \operatorname{Asn}(\operatorname{Trt}), \quad \operatorname{Asp}(\mathrm{OtBu}), \quad$ Cys(Trt), Gln(Trt), Glu(OtBu), His(Trt), Lys(Boc), Ser(tBu), $\operatorname{Thr}(\mathrm{tBu}), \operatorname{Trp}(\mathrm{Boc}), \operatorname{Tyr}(\mathrm{OtBu})$. Couplings were for 30 min using a 4-fold excess of 9-fluorenylmethoxycarbonyl (Fmoc) amino acid in the presence of 0.98 equivalents of HATU: (O-(7-azabenzotriazoly-1-yl)$\mathrm{N}, \mathrm{N}, \mathrm{N} 9 \mathrm{~N}$-tetramethyluronium hexafluorophosphate) and 1.96 equivalents of Hünig's base. Peptides were cleaved from the resins with 91:3:3:3 (v/v/v/w) trifluoroacetic acid (TFA)/ethanedithiol/ triethylsilane/phenol for $5 \mathrm{hr}$ and products were purified by preparative reverse-phase HPLC on a Vydac 208TP1022 C8 $200320 \mathrm{~mm}$ column using gradients of acetonitrile in $0.1 \%$ aqueous TFA. Purified products were analyzed by a) amino acid analysis on a Pharmacia-Biochrom 20 amino acid analyzer following hydrolysis in $6 \mathrm{M} \mathrm{HCl}$ for $18 \mathrm{hr}$ at $1108 \mathrm{C}$ and b) MALDI-TOF mass spectrometry on a PerSeptive Biosystems Voyager Mass Spectrometer using alphacyano-4-hydroxycinnamic acid (CHCA) matrix to confirm the correct mass. The sequences employed were as follows:

ARP (Acetylcholinesterase Readthrough Peptide) 1-GMQGPAGSGWEEGSGSPPGVTPLFSP-26

ASP (Acetylcholinesterase Synaptic Peptide, corresponding to the AChE-S C-terminal domain) 1-DTLDEAERQWKAEFHRWSSYMVHWKQFDH YSKQDRCSDL-40

PBAN, insect pheromone peptide was as published (36).

\section{Antisense Oligonucleotides}

To suppress AChE expression, a 20-mer antisense oligonucleotide, AS1, targeted to exon 2 of mammalian AChE mRNAs was used (59GGGAGAGGAGGAGGAAGAGG-39) (23). A 15-mer oligonucleotide targeted to butyrylcholinesterase (BChE) mRNA, previously shown to be inert with regard to AChE mRNA, served as control (59-GACTTTGCTATGCAT-39) (29,37). To protect against nuclease degradation, all oligonucleotides were end-capped 
at their three 39 terminal positions by 290 -methyl ribonucleotides.

\section{Clonogenic Progenitor Assays}

Human clonogenic progenitors were cultured in the presence of various growth factors and colony-forming progenitors were assessed at weekly intervals in secondary colony assays. Granulocyte-macrophage colony-forming units (CFU-GM) and blast cell colonies were grown in IMDM containing $0.9 \%$ methylcellulose and $10 \%$ fetal calf serum (FCS), $5 \mathrm{ng} / \mathrm{ml} \mathrm{IL-3}$, and $10 \mathrm{ng} / \mathrm{ml}$ granulocyte-macrophage colony stimulating factor (GM-CSF), and counted after 12-14 days. Megakaryocyte colony forming units (CFU-MK) were grown in plasma clots containing $15 \%$ AB plasma, $10 \mathrm{ng} / \mathrm{ml}$ TPO and $10 \mathrm{ng} / \mathrm{ml} \mathrm{SCF}$, and identified and counted by immunofluorescence after 12-14 days in culture as previously described (38). Mixed colonies including granulocytes, erythrocytes, macrophages, and megakaryocytes (CFU-GEMM) were identified as very large, multilineage colonies containing more than 200 cells. The multilineage content was verified by microscopic analysis of stained cells from representative colonies. The absolute number of CFU-GEMM, CFU-GM, CFU-MK, and CFU-blast colonies grown at each time point during the culture was calculated by multiplying their incidence (per cells seeded in colony assay) by the number of viable nucleated cells present in each liquid culture.

Murine clonogenic progenitors were cultured at $2310^{5}$ cells per $35 \mathrm{~mm}$ tissue culture dishes (Corning Glass Works). Myeloid colonies were grown in supplemented IMDM (Beit Haemek) supplemented with $0.8 \%$ methylcellulose (Sigma), $10 \%$ FCS (Beit Haemek), and $531^{4} \mathrm{M} \beta$ mercaptoethanol (2-ME) (Sigma). Myeloid colony formation was stimulated with recombinant mouse (rm) GM-CSF $(5 \mathrm{ng} / \mathrm{ml})$, rmSCF $(10 \mathrm{ng} / \mathrm{ml})$, and r-mIL3 (10 ng/ml) (R\&D Systems) in 5\% $\mathrm{CO}_{2}$ at $378 \mathrm{C}$ in a fully humidified atmosphere. Colonies were counted in triplicate cultures after 7 days. MK colonies were grown in supplemented McCoy's medium (Beit Haemek) supplemented with $0.3 \%$ agar (Difco), 10\% FCS, and $131^{24}$ M 2-ME. Colony formation was stimulated with rm thrombopoietin $(2 \mathrm{ng} / \mathrm{ml})$ and $\mathrm{rmSCF}(10 \mathrm{ng} / \mathrm{ml})$ (R\&D Systems) in $5 \% \mathrm{CO}_{2}$ at $378 \mathrm{C}$ in a fully humidified atmosphere. CFU-MK were identified by specific cytochemical staining as described (22) and counted after 7 days.

\section{Flow Cytometric Analysis of Cultured CD34 $4^{1}$ Cord Blood Cells}

To determine the type of cells that were expanded in the presence of the different cytokines, three-color flow cytometry was performed at weekly intervals. For fluorescent activated cell sorter (FACS) analysis of hematopoietic cells, the following antibodies were employed: perCP conjugated anti-CD34, HPCA-2 (Becton-Dickinson), phycoerythrin (PE) conjugated-anti-CD38 (Becton-Dickinson), PE antiCD33 (Becton-Dickinson), PE-anti-CD41 (BectonDickinson), or FITC-conjugated anti-CD41 (P2) (Immnunotech/Coulter, England), FITC-conjugated anti-CD15 (Becton-Dickinson). Multiparameter flow cytometry was performed using a FACScalibur (Becton-Dickinson) and Cellquest software (Becton-Dickinson) on a minimum of 10,000 events analyzed per sample. Nonspecific labeling was excluded using the appropriate isotype antibodies conjugated with the same fluorochrome (BectonDickinson). The actual number of expanded cells of each lineage was calculated by multiplying their relative proportion by the number of viable cells in each culture.

\section{Protein Blots}

Serum proteins $(40 \mu \mathrm{g})$ were separated on $4-20 \%$ polyacrylamide gels (Bio Rad Laboratories, Hercules, Calif), blotted to nitrocellulose filters, incubated with rabbit anti-GST-ARP antibodies (30) and peroxidaseconjugated anti-rabbit immunoglobulins, and subjected to ECL detection (Amersham Pharmacia Biotech, Buckinghamshire, UK).

\section{Results \\ Hematopoietic and Stress-Responsive Elements in the Extended ACHE Gene Promoter}

In the mammalian nervous system, AChE-R is upregulated in response to acute cholinergic stimulation such as that accompanying traumatic stress (28), anticholinesterase intoxication (39), and closed head injury (29). To explore the possibility that AChE-R operates as a stress-response element in the hematopoietic system as well, we searched the extended promoter of the human ACHE gene (cosmid accession no. AF002993) for consensus motifs encoding cis-acting binding sites for stress-associated and hematopoietic transcription factors. Two such clusters, one a functional promoter domain located $17 \mathrm{~Kb}$ upstream from the transcription start site (40) and another positioned within the first intron, were found to include glucocorticoid responsive element (GRE) half-palindromic sites TGTTCT, as well as motifs for AP1, NFkB, EGR-1 (as identified by a matrix search against the TransFac database), HNF $3 \beta$, with the consensus sequence TGTTGT, and Stat-5, TTCCCAGAA or TT(C/A)(C/T)N(A/G) (G/T)AA (Fig. 1A). Of these, GRE, HNF3, and Stat-5 are known to be actively involved in hematopoiesis (41) and cellular stress responses $(42,43)$. GRE and Stat5 act synergistically to enhance $\beta$-casein gene expression in mammary tissue (44), but have not yet been studied in the context of AChE involvement in hematopoiesis. 

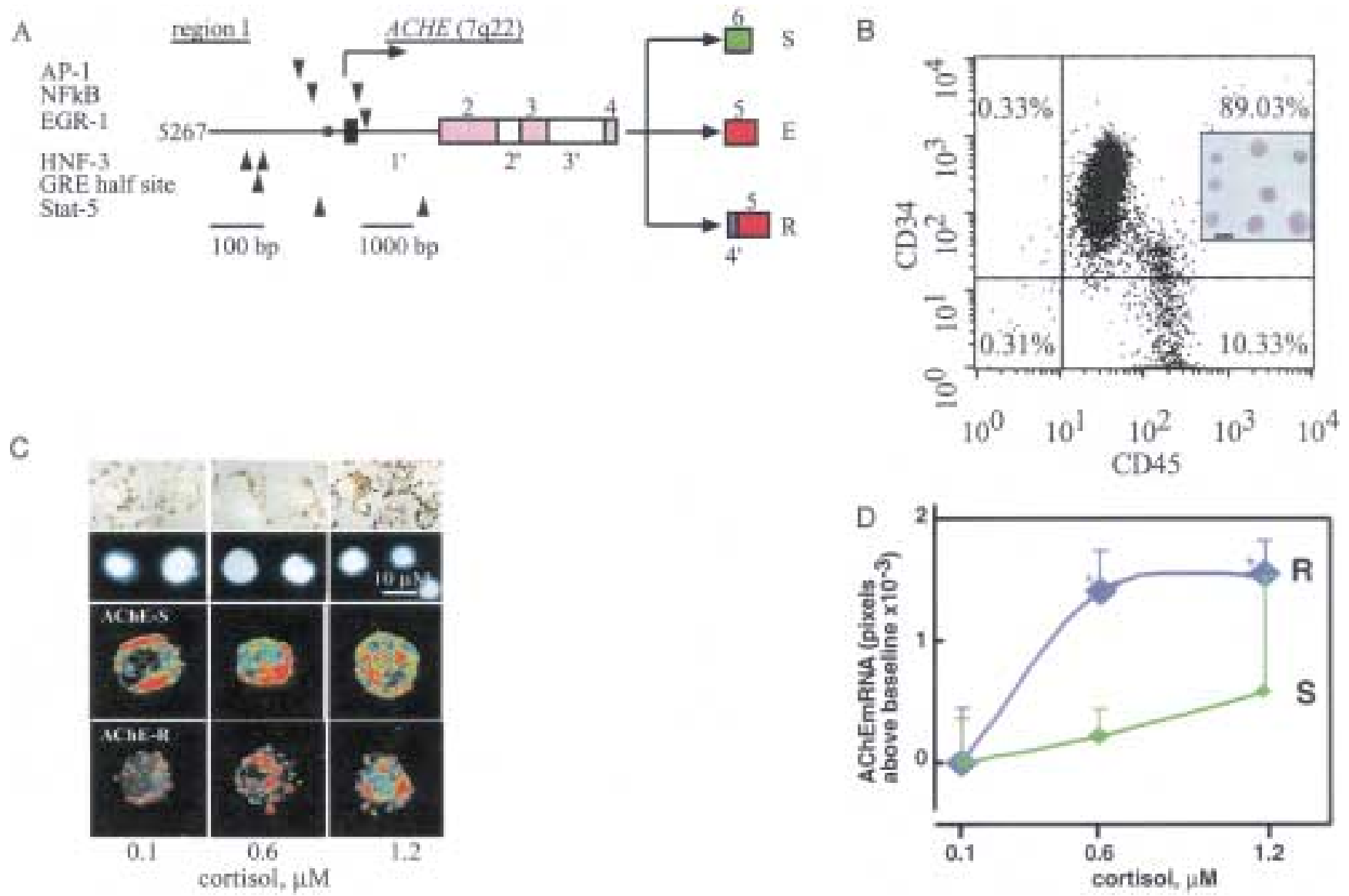

Fig. 1. Cortisol up-regulates AChE-R expression in human CD34 ${ }^{+}$cells. (A) The upstream human ACHE sequence includes clusters of hematopoietic and stress-related motifs. Depicted is the reverse sequence of the cosmid insert (accession no. AF002993) of the human $A C H E$ promoter. The arrow represents the position of a transcription start site. Two potentially relevant regions are shown, one beginning at nucleotide 5267 and one following the first exon (black box). Fully conserved consensus sequences are marked by triangles, and the scale in base pairs (bp) is shown below. Note the presence of a GRE half site and two functionally interdependent sites for binding of hepatic nuclear factor $\left(\mathrm{HNF}_{3}\right)$ [based on (40)]. (B) Enrichment of UCB CD34 ${ }^{1}$ cells. CD $34^{1}$ cells were enriched from human UCB cells using bead-attached antibodies to the CD34 protein. Shown is a representative flow cytometry of the recovered cells, demonstrating that $89 \%$ express the CD34 antigen. Inset: Example photograph of enriched CD $34^{1}$ cells stained by May-GrünwaldGiemsa. Note the large nuclei surrounded by thin rims of cytoplasm, characteristic of stem cells. (C, D) Cortisol stimulates expression of AChE mRNA splicing variants. Shown are CD $34^{1}$ cells treated with the noted concentrations of cortisol equivalent to physiologically normal $(0.1 \mu \mathrm{M})$, mild stress $(0.6 \mu \mathrm{M})$, and acute stress conditions $(1.2 \mu \mathrm{M})$. (C) Presented are cytochemically stained cells (top) and pseudocolor representations of 3-dimensional projections created from confocal scanned images of CD34 ${ }^{1}$ cells following in situ hybridization with the noted 59biotinylated 290-methyl cRNA probes selective for the synaptic AChE-S and readthrough AChE-R mRNA variants. Note increasing red cytoplasmic labeling under high cortisol levels. Each photograph represents one of 10-20 analyzed cells with deviations in labeling of less than $6 \%$. (D) Shown are the results of semiquantitative image analysis of in situ hybridization for each AChE mRNA transcript under stress-relevant concentrations. Note that only AChE-R mRNA accumulated under moderate cortisol concentrations. Asterisks denote statistical significance $(p, 0.05$, ANOVA).

\section{Cortisol Elevates ACHE Gene Expression in Hematopoietic Progenitors}

The functional effects of glucocorticoids on hematopoietic ACHE expression were investigated in early human progenitors enriched from UCB using immune magnetic beads for CD34 to yield a $8563 \%$ pure population of $\mathrm{CD} 34^{1}$ cells, as confirmed by flow cytometry (Fig. 1B). CD $34^{1}$ cells were cultured for $24 \mathrm{hr}$ with increasing concentration of cortisol and subjected to in situ hybridization, confocal microscopy, and semiquantitative image analysis. This approach provided an accurate and credible tool for the quantification of transcriptional responses in the heterogeneous population of primary 
CD $34^{1}$ cells pooled from different individuals. Figure IC presents representative images of cells analyzed for AChE-S and AChE-R mRNAs, and the quantified changes in mRNA levels under treatment with different cortisol concentrations. A subtle elevation of cortisol concentration from a basal level of $0.1 \mu \mathrm{M}(45)$ to $0.6 \mu \mathrm{M}$ induced a selective 1306 $30 \%$ increase in the area labeled by the AChE-R mRNA probe. In contrast, a stress-associated cortisol concentration of $1.2 \mu \mathrm{M}$ increased the areas labeled by both AChE-R and AChE-S mRNA probes. Cytochemical staining revealed active enzyme only under $1.2 \mu \mathrm{M}$ cortisol at which concentration the membrane associated enzyme forms AChE-E and AChE-S were expressed (Fig. IC and data not shown). This observation is consistent with the secretory nature of AChE-R. Together, these observations demonstrated cortisol-inducible expression of AChE-R in hematopoietic progenitors (Fig. 1D), and suggested that stress-promoted modulation of $A C H E$ gene expression and alternative splicing may play an active role in mediating hematopoietic stress responses.

\section{A Bioactive Peptide Derived From AChE-R Evokes Potent Hematopoietic Effects}

To determine whether AChE- $R$ is present in the blood and whether its level is regulated by stress, we employed antibodies raised against a recombinant fusion protein of glutathione transferase (GST) and ARP. Anti-GST-ARP antiserum reacted with AChE-R but not AChE-S in Western blots (Fig. 2A). We therefore subjected FVB/N mice to confined swim stress, collected blood after $24 \mathrm{hr}$, and performed denaturing gel electrophoresis on serum proteins. Immunodetection with anti-GST-ARP antibodies failed to detect major changes in circulating levels of AChE-R following stress. However, GSTARP antiserum reacted with a novel short peptide with an apparent molecular weight of approximately $5.0 \mathrm{Kd}$ in serum of stressed mice. The appearance of a short, ARP-related peptide in blood following forced swim suggested that cleavage of AChE-R generates a peptide with a role in hematopoietic stress responses.

To explore the idea that ARP promotes stressinduced hematopoiesis, we employed synthetic ARP peptide. Mice subjected to confined swim stress were injected intravenously with $100 \mu \mathrm{g} / \mathrm{Kg}$ ARP or $30 \mathrm{ng} / \mathrm{Kg} \mathrm{AS1,} \mathrm{an} \mathrm{antisense} \mathrm{oligonucleotide}$ preferentially suppressing AChE-R $(23,29)$. Twentyfour hours later, bone marrow smears were prepared and immunostained with anti-GST-ARP antibodies. In addition, peripheral white blood cell (WBC) counts were performed. In nonstressed mice, ARP did not significantly change bone marrow labeling or WBC counts. In stressed mice, however, ARP both elevated the number of ARP-positive cells and intensified the immunolabeling in small cells with morphologic features of stem cells (Fig. 2B). AS 1 reduced the number of cells labeled with anti-GSTARP antibodies, indicating that injected ARP amplified endogenous ARP production under stress. Consistent with this hypothesis, AS I also reduced WBC counts, suggesting that induced AChE-R and/or cleaved ARP participate in the characteristic stressrelated release of WBC from the bone marrow to the periphery.

To evaluate the status of multipotent hematopoietic progenitors in the bone marrow of treated mice, we performed clonogenic progenitor assays where primary bone marrow cells are plated under conditions supporting the growth of specific hematopoietic lineages. Following 1 week in culture, colonies were classified as granulocyte/erythrocyte/myeloid/ macrophage (GEMM), granulocyte/macrophage(GM), or megakaryocyte (MK) colonies and counted. In this assay, each colony is taken to represent a single plated progenitor or colony-forming unit (CFU). Significant increases were noted in CFU-GEMM and CFU-MK from stressed, as compared with nonstressed animals (Fig. 2C). ARP potentiated stress effects with regard to CFU-MK, and exerted profound effects on both CFU-MK and CFU-GEMM when administered to nonstressed animals (Fig. 2C). In contrast, no significant changes were found in the more differentiated granulocyte-macrophage CFU-GM progenitors 7 days after plating (data not shown). Together with the bone marrow immunolabeling, these data indicate a dual role for ARP in the expansion of both megakaryocyte and myeloid progenitors.

\section{ARP Promotes Ex Vivo Progenitor Cell Proliferation Under Antisense Suppression of AChE-R mRNA}

To demonstrate a specific role for AChE-R and/or ARP in hematopoiesis, we employed very low concentrations of ASl in ex vivo cultures of human CD $34^{1}$ cells. At picomolar concentrations, AS 1 demonstrated highly discriminative preference for AChE-R versus AChE-S mRNA (Fig. 3A). At this concentration, an irrelevant oligonucleotide targeted to butyrylcholinesterase mRNA (ASB) exerted a very limited effect on AChE mRNA and activity levels [(23) and data not shown]. DNA synthesis in treated cultures was studied by following the incorporation of $\mathrm{BrdU}$ as a measure of stem cell proliferation in short-term cultures. Together with GM-CSF, $50 \mathrm{ng} / \mathrm{ml}$ (approximately $2 \mathrm{nM}$ ) ARP induced a linear increase in BrdU incorporation from 16-36 hrs compared to GM-SCF alone (Fig. 3B and data not shown). No such effect on proliferation was observed when synthetic AChE-S C-terminal peptide, ASP, was substituted for ARP (data not shown). BrdU incorporation was partially suppressed by 20 pM AS 1 , but antisense suppression was completely overridden by ARP (Fig. 3B). The observation that antisense blockade of mRNA encoding full-length AChE-R failed to inhibit the proliferative effects of ARP reinforced the notion that ARP peptide is sufficient, in the absence 

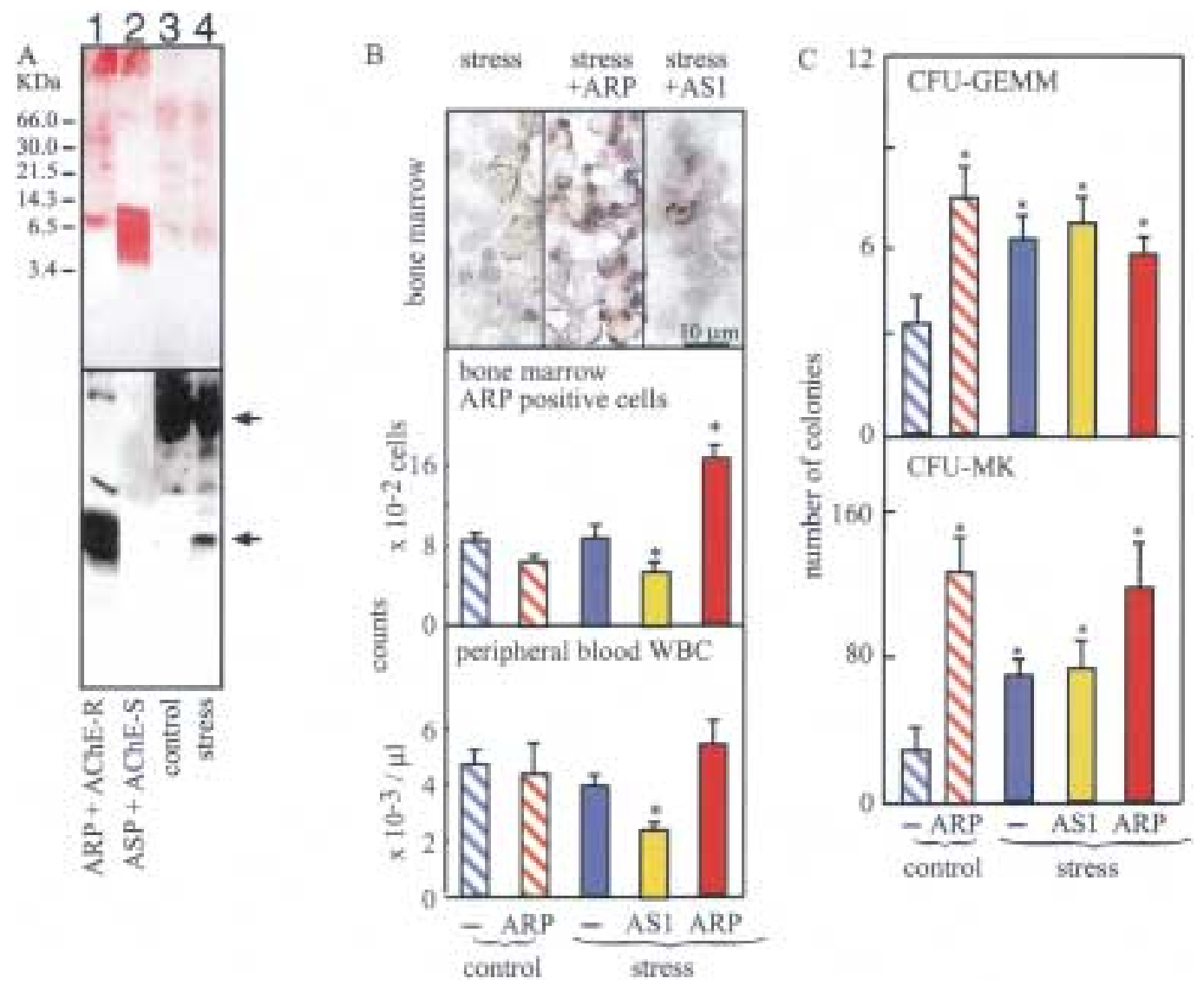

Fig. 2. ARP has short- and long-term hematologic effects in vivo. (A) ARP accumulates in the serum under stress. Top: Shown are Ponceau-stained lanes of gradient polyacrylamide gels (4-20\%, Bio-Rad) loaded with 1) protein extract from COS cells transfected with AChE-R encoding plasmid and mixed with synthetic ARP, 2) recombinant human AChE-S (Sigma) mixed with synthetic ASP, 3) $2 \mu \mathrm{l}$ serum from a mouse injected with saline, or 4) a mouse subjected to confined-swim stress 24 hr posttreatment. Positions of molecular weight markers are shown on the left. Bottom: The above shown gel was electroblotted and probed with affinity-purified rabbit antibodies elicited toward a recombinant GST-ARP fusion protein. Note labeling in the serum of a 67-KDa protein, consistent with the expected size of AChE-R; also note selective labeling of synthetic ARP (but not AChE-S or ASP) by this antibody and the appearance of a novel immunoreactive band of approximately $5 \mathrm{Kd}$ in serum of the stressed mouse. (B) ARP facilitates stress-induced hematopoietic responses in vivo. Top panel: Shown are bone marrow smears immunostained with anti-GST-ARP antibodies. Note that ASl reduced and ARP intensified immunolabeling (brown precipitates) and increased the number of small ARP-positive cells in stressed mice. Middle panel: Number of ARP-immunopositive cells in bone marrow from the noted groups of FVB/N mice; the graph represents an average of five different fields counted at 31000 magnification for bone marrow. Bottom panel: Peripheral white blood cell counts. Note that both bone marrow immunostaining and white cell counts revealed ARP-dependent elevations and ASl suppression ( $n 512$ mice per ARP and ASl treated stress groups). Control, nonstressed FVB/N mice were injected intraperitoneally with normal saline ( $n 56)$ or ARP $\left(\begin{array}{l}n \\ 5\end{array}\right.$ 4). (C) Clonogenic progenitor cultures. Bone marrow cells from the noted groups of mice were subjected to clonogenic progenitor assays as described in methods. Top: myeloid CFU-GEMM; bottom: CFU-MK. Asterisks denote statistical significance $(p, 0.05$, ANOVA). Increased numbers of CFU reflects increased numbers of viable progenitors able to give rise to each of the assayed cell lineages.

of intact AChE-R, to promote expansion of CD34 ${ }^{1}$ hematopoietic progenitor cells.

\section{ARP Potentiates Myelopoiesis and Megakaryocytopoiesis Ex Vivo}

To further demonstrate the hematopoietic potency of ARP, we studied CD $34^{1}$ progenitor cell development over 2 weeks in liquid culture in the presence of synthetic ARP, cortisol, or SCF. ASP, PBAN [an irrelevant insect peptide of similar size (36)], or AS I served as controls. Early and late myeloid and MK progenitor cells were labeled with fluorescent monoclonal antibodies detecting commitment- and maturation-specific cell surface markers, and flow cytometry revealed the distinct cell populations generated under the different growth conditions. Ex vivo, micromolar cortisol concentrations exerted significant enhancement of both myeloid and megakaryocyte progenitor populations (Table 1 and Fig. 4). Thus, cells positive for early and mature myeloid cell markers (Fig. 4, top row) as well as proliferating MK progenitors positive for both CD34 and CD41 (Fig. 4, bottom row) increased in numbers in the analyzed cell populations. At 1000-fold 

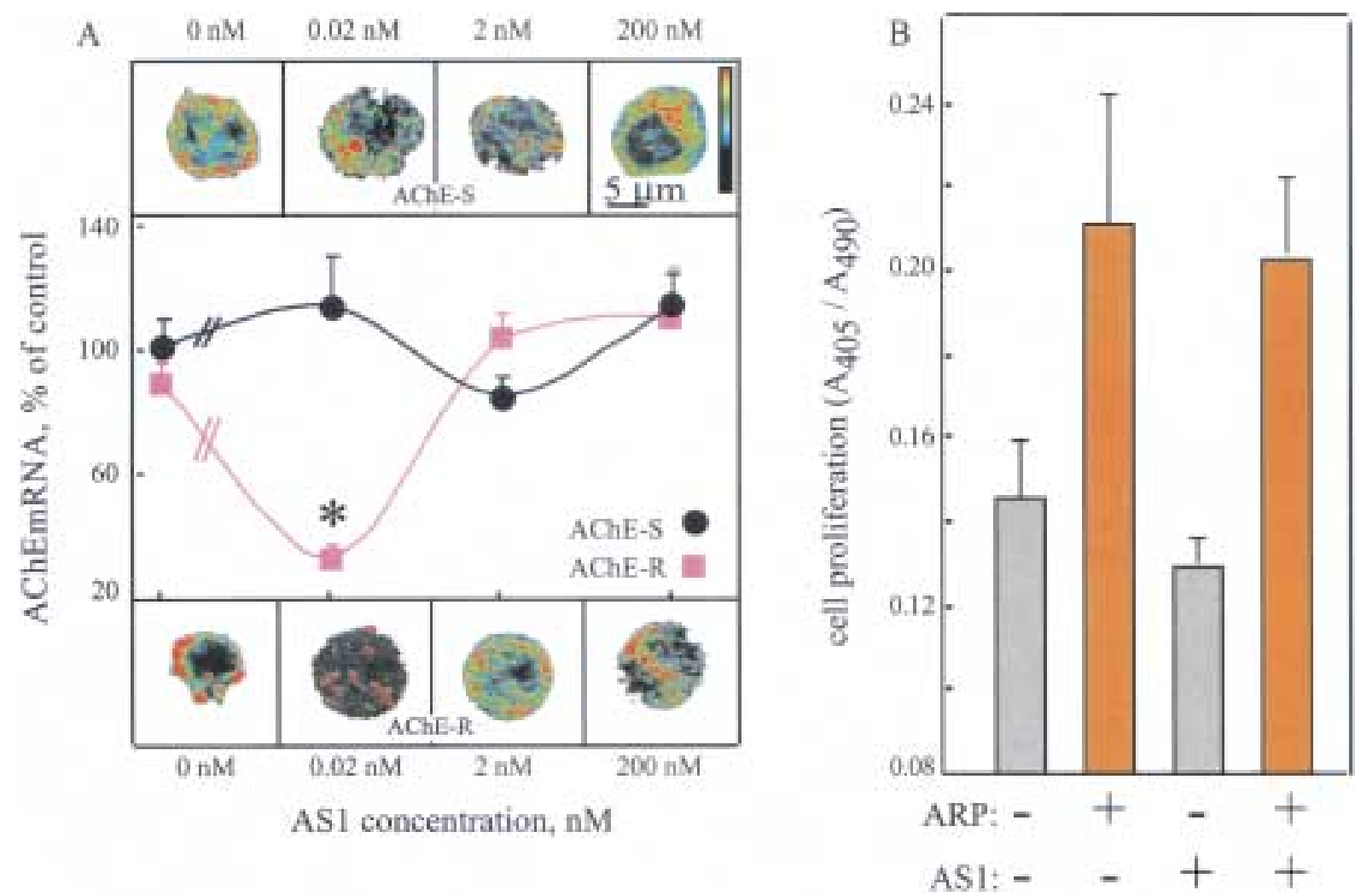

Fig. 3. ARP facilitates, and AS1 suppresses proliferation of CD34 ${ }^{+}$progenitors. (A) Low concentrations of AS 1 selectively suppress AChE-R in human CD $34^{1}$ progenitors. Human CD $34^{1}$ cells were incubated for 24 hr with the noted concentrations of AS 1, an antisense oligodeoxynucleotide targeted to exon 2 in AChE mRNA. Shown are confocal images taken following in situ hybridization with cRNA probes for the noted transcripts. Graph shows an inverted, sequence-specific, dose-dependent suppression of AChE-R mRNA in CD $34^{1}$ cells by AS1. Shown are average fluorescent signals 6 SD measured in confocal projections (20 cells per group) of CD $34^{1}$ cells treated with ASI and subjected to in situ hybridization with AChE-S and -R specific probes. Asterisks note statistically significant differences from control $(p, 0.001$, Student's $t$-test). (B) ARP enhances cell proliferation. Cell proliferation was evaluated by measuring BrdU incorporation following $16 \mathrm{hr}$ incubation in the presence of GM-CSF with or without $50 \mathrm{ng} / \mathrm{ml}$ ARP and $20 \mathrm{pM}$ of AS 1. Presented are average results of three to six reproducible experiments 6 SEM. Note that ARP enhances GM-CSF-supported increases in cell proliferation, that ASI attenuates this enhancement and that ARP overrides antisensesuppressed proliferation.

Table 1. The effect of various conditions on cultured cell counts ${ }^{a}$

\begin{tabular}{|c|c|c|c|c|c|}
\hline Treatment & $\begin{array}{c}\text { Total } \\
\text { Viable Cells }\end{array}$ & $\begin{array}{c}\text { CD34 }^{+} \\
\text {(Early Progenitors) }\end{array}$ & $\begin{array}{c}\mathrm{CD}^{+} 3^{+} \\
\text {(Early Myeloids) }\end{array}$ & $\begin{array}{c}\mathrm{CD}^{+} 3^{+} \text {and CD15 } \\
\text { (Total Myeloids) }\end{array}$ & $\begin{array}{c}\mathrm{CD}^{+}{ }^{+} \\
\text {(Megakaryocytes) }^{\text {Megalo }}\end{array}$ \\
\hline Control & 61.0 & 1.0 & 7.2 & 12.3 & 30.9 \\
\hline ARP, $2 \mathrm{nM}$ & 570.0 & 87.2 & 329.0 & 530.0 & $42.3^{b}$ \\
\hline Cortisol, $1.2 \mu \mathrm{M}$ & 80.0 & 13.0 & 45.0 & 73.0 & $10.1^{b}$ \\
\hline ASP, 2nM & 100.0 & 7.2 & 10.0 & 13.0 & $4.6^{b}$ \\
\hline $\mathrm{SCF}, 50 \mathrm{ng} / \mathrm{ml}$ & 118.0 & 6.3 & 69.0 & 72.0 & $2.6^{b}$ \\
\hline AS 1, 20 pM & 81.2 & 1.4 & 2.4 & 5.0 & 30.9 \\
\hline PBAN, $2 n M$ & 105.0 & 1.7 & 1.6 & 3.1 & 52.9 \\
\hline
\end{tabular}

${ }^{a}$ Cultures were seeded at 50,000 cells/well. Shown are cells per culture $310^{23}$ on day 14 ; one of three reproducible experiments.

${ }^{b}$ These are also $\mathrm{CD} 34^{1}$ positive early cells with expansion potential. 


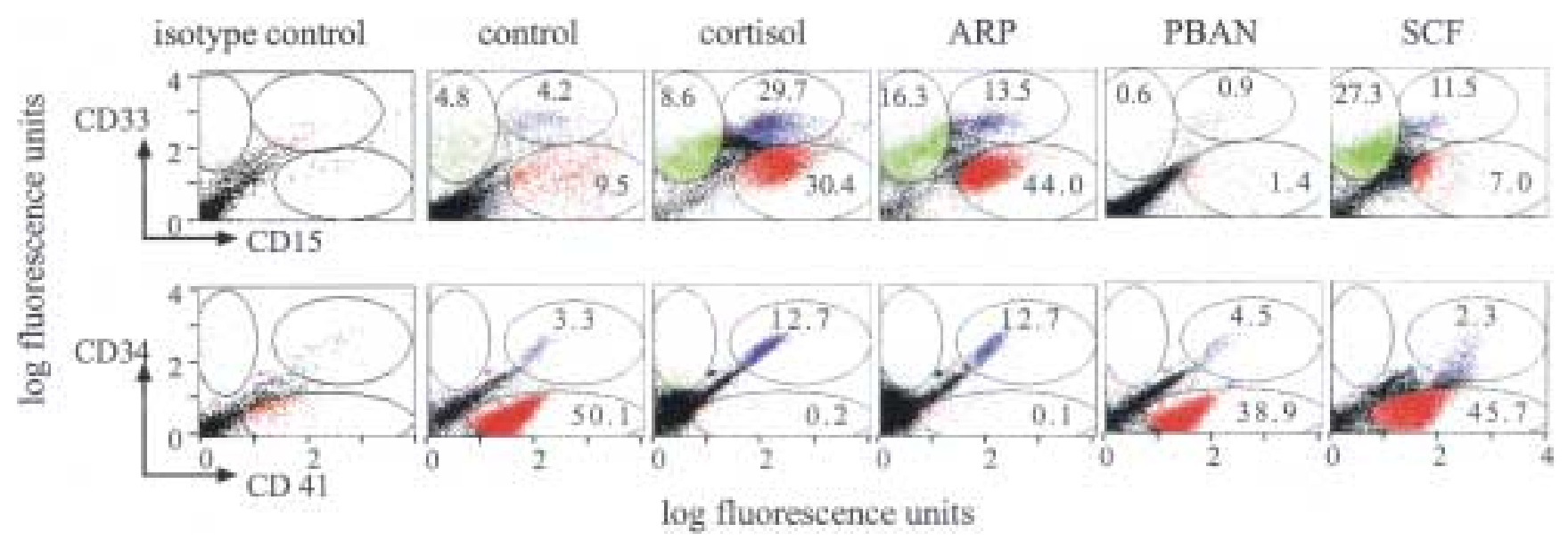

Fig. 4. Cortisol and ARP support myeloidogenic and megakaryocytic expansion ex vivo. Flow cytometric analysis of CD $34^{1}$ derived hematopoietic cells was performed after 2 weeks in liquid culture. Each analysis included 10,000 events and regions were set according to the appropriate isotype controls to exclude nonspecific labeling (first column). The percentage of myeloid (top row) and megakaryocytic (bottom row) cells that developed in the presence of each growth supplement is indicated by numbers on the relevant dot plots. Unlabeled cells appear as black dots, double labeled, as blue dots.

lower concentrations, ARP proved to be an even more powerful stimulator of $\mathrm{CD} 34^{1}$ cell expansion than either cortisol or SCF. The antigenic profiles and the relative proportions of the distinct progenitor populations that emerged with ARP or cortisol appeared similar, indicating a common pathway through which ARP or cortisol stimulate hematopoiesis. In contrast, ASP and PBAN had few or none of these effects. SCF, as expected, potentiated expansion of both MK and myeloid progenitors (34). However, far fewer early CD $34^{1}$ progenitors were detected. In contrast, ASI suppressed myelopoiesis and proliferating MK progenitors (Table 1). These findings further supported the notion that ARP or an ARP-related peptide derived from AChE-R exerts potent, physiologically relevant effects on mammalian hematopoiesis. Furthermore, they lent credence to the idea that ARP may be applied to therapeutic protocols involving ex vivo expansion of hematopoietic stem cells.

\section{ARP Can Substitute for SCF Ex Vivo}

To determine whether ARP could replace any of the known growth factors in a longer ex vivo context, we tested ARP alone or combined with known growth factors on 4 -week $\mathrm{CD} 34^{1}$ cell cultures. To enable long-term expansion of early progenitors, a cocktail of early-acting cytokines (growth factor cocktail [GFC] containing IL3, IL6, TPO, and FLT3) was used. These conditions supported expansion of $\mathrm{CD} 34^{1}$ cells for up to 28 days in liquid culture (Fig. 5A). In the absence of cytokines, however, there was no cell proliferation and the number of viable cells progressively declined. SCF, devoid of proliferative activity alone, enhanced the proliferation induced by early-acting cytokines. ARP supported proliferation similar to that achieved with SCF. Moreover, the proliferative effects of SCF and ARP together led to a greater than 10- to 100-fold expansion of viable cells within 28 days (Fig. 5A). These data demonstrated that the activity of ARP is additive to those of both the early-acting cytokines and that it could replace SCF in supporting progenitor cell proliferation. To evaluate the capacity of progenitors expanded under the various liquid culture conditions to differentiate into different hematopoietic lineages, we sampled the cultures weekly and performed clonogenic assays in the presence of specific growth factors. In the presence of GFC, both ARP and SCF exerted a minimal 2- to 3fold elevation in the formation of colonies containing undifferentiated blast cells (CFU-blast) (Fig. 5B). Together, ARP and SCF displayed a potent, synergistic enhancement in CFU-blast formed from cells seeded after 14 days in liquid culture. ARP demonstrated an equal or superior potency in promoting CFU-GM and CFU-MK compared to SCF (Fig. 5CD) and no synergistic effects between ARP and SCF were observed under these conditions.

In CD $34^{1}$ liquid cultures grown without growth factors for 28 days, cells displayed a typical fibroblast morphology (Fig. 5E). In contrast, a dense population of small round cells with characteristic stem cell morphology was observed in cultures supplemented with early-acting cytokines and SCF (Fig. 5F). This stem cell morphology was also observed when ARP was either combined with or substituted for SCF in the cultures (Fig. 5GH). Notably, floating "hematons," which are independent hematopoietic units rich in myeloid, erythroid, and MK progenitors (46) were observed only in ARP-containing cultures (Fig. 5GH insets). The hematologic and fibroblast content of these hematopoietic bodies was verified 


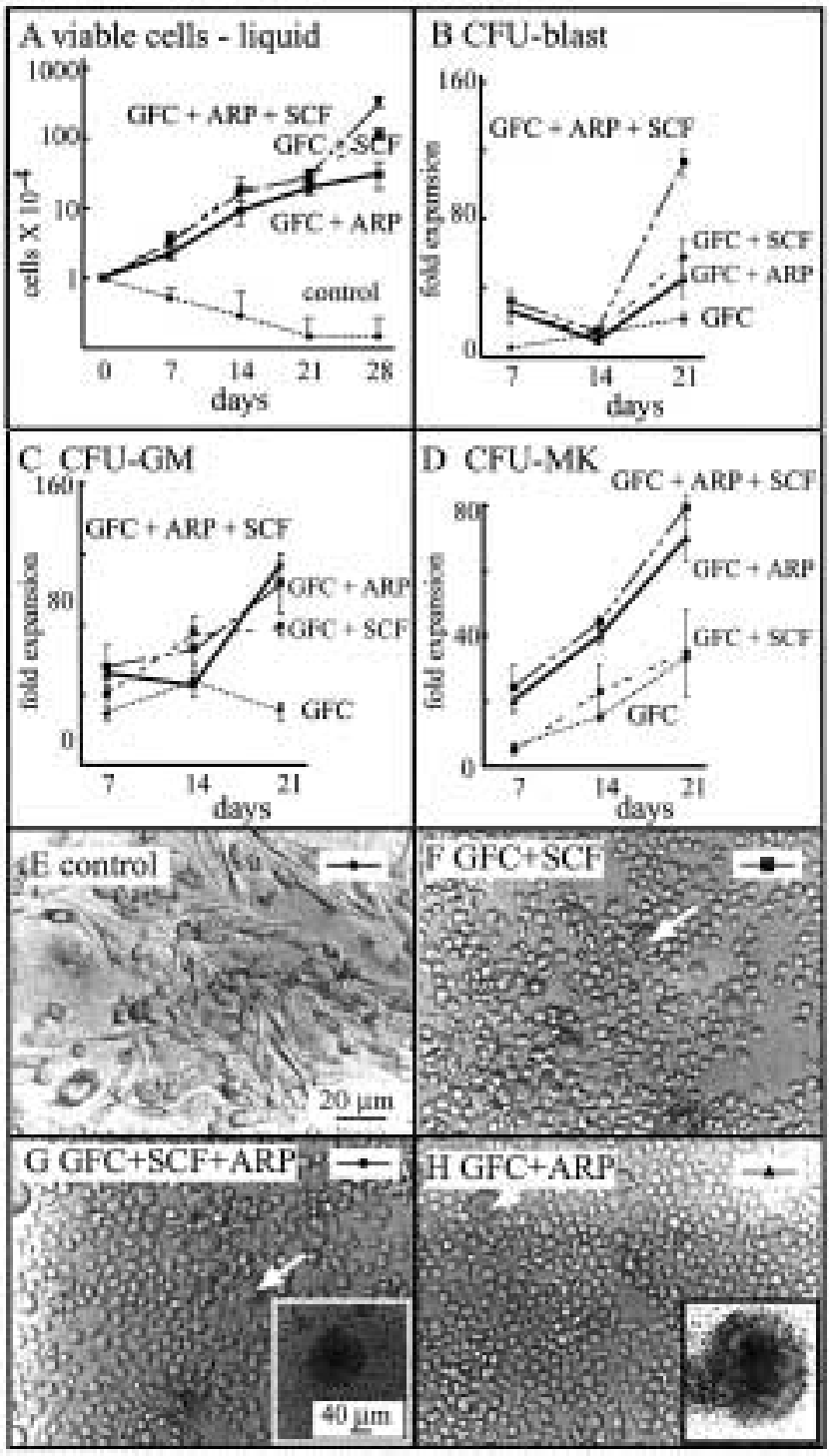

Fig. 5. Potent activity of ARP on progenitor cell expansion and differentiation. (A) Effects on cultured cell viability and proliferation in liquid cultures. Human $\mathrm{CD}_{3} 4^{1}$ cells were cultured $\left(10^{5}\right.$ cells $\left./ \mathrm{ml}\right)$ in 24 -well tissue culture plates and grown in IMDM containing $10 \%$ autologous plasma and early-acting cytokines: IL-3 (5 ng), IL-6 (50 ng), TPO (10 ng), FLT-3 ligand (FL, $10 \mathrm{ng}$ ), to which stem cell factor (SCF, $10 \mathrm{ng}$ ) and/or the synthetic AChE-R peptide (ARP, $2 \mathrm{nM}$ ) were added. Note that ARP can replace SCF in inducing hematopoietic cell proliferation and that ARP1 SCF exert synergistic effects under prolong culture conditions. Average 6 SD of four experiments. (B-D) Progenitor cell assays. The presence of CFU progenitors was assessed at weekly intervals in secondary colony assays. CD $34^{1}$ progenitors were grown in primary liquid cultures as in Fig. 5A for the noted time, plated in colony assays, and counted after 12-14 days. All cultures contained a combination of growth factors (GFC: IL-3, IL-6, TPO, and FL) to which were added ARP and/or SCF, as noted. Note that ARP can replace SCF in proliferating progenitors for MK and GM, but not blast colonies. Nevertheless, ARP and SCF together exert synergistic effects on CFU-blast. Data are averages of four experiments 6 SEM. (E-H) ARP facilitates development of hematon bodies. Shown are representative photographs of the 28 -day liquid cultures detailed in Fig. 5A. (E) In the absence of growth factors, sparse hematopoietic cells and many fibroblasts are seen. microscopically by cell morphology. The presence of hematons in the cultures further reinforces the differentiation-promoting potential of this peptide.

\section{Discussion}

\section{ARP Potentiates Cortisol Effects}

We found that ARP, like cortisol, accumulates in the serum following acute stress and facilitates the cytokine-induced proliferation of human CD $34^{1}$ hematopoietic progenitors along the myeloid and MK lineages. ARP accumulation may involve stressinduced transcriptional activation (47), modulation of alternative splicing $(48,49)$, changes in the lifespan of AChE-R mRNA (50), enhanced proteolytic activity (51), or a combination of these processes. Our current findings demonstrate that the cortisolinduced accumulation of ARP can potentiate and extend its hematopoietic effects long after cortisol itself ceases to be produced, as would be required from long-lasting modulators of blood cell composition. Likewise, the effects of ARP on adherent cell foci suggest its involvement in the proliferation and differentiation of mesenchymal stroma and/or endothelial cells, both of which influence cytokine production and hematopoietic homeostasis through a cross-talk with $\mathrm{CD} 34^{1}$ progenitors $(52,53)$.

\section{ARP Joins a Family of Hematopoietically Active Short Peptides}

In x-ray crystallography models of Torpedo AChE, the C-terminus was unresolved (54). C-terminal sequencing of highly purified fetal bovine serum AChE-S (B. P. Doctor, personal communication) demonstrated cleavage at, or near, the splice site. Together, these findings indicate a loose structure that may be susceptible to cellular proteases, and a flexibility that may enable binding to other proteins. The apparent natural cleavage of AChE-R and AChE-S invites a search for morphogenic effects attributable to ARP, ASP, or related peptides. Studies are under way to determine the exact cleavage site giving rise to circulating ARP-related peptide and to identify the protease(s) responsible for this activity.

ARP does not display homology to any known hematopoietic growth factor. Nevertheless, other short peptides were shown to exert growth factor-like activities. Several synthetic hematopoietically active short peptides are known, some of which are homologous to natural peptides or protein domains [e.g., the CC' surface loop of CD4 (55)]. Others share biological function, but not sequence, with natural larger proteins. For example, a synthetic

(F) Either SCF or (H) ARP increases the density of small, round hematopoietic stem cells and sparse MKs (white arrows). (H) GFC 1 ARP facilitate the formation of hematon bodies (insets) without $(\mathrm{H})$ or with SCF (G). 
20-residue cyclic peptide (56) and its 13-residue derivative (57) mimic the interaction of the 166-residue hematopoietic growth hormone erythropoietin (EPO). Similarly, a 14-amino acid peptide was discovered, and is equipotent to the 332-amino acid cytokine TPO (58). ARP displayed an independent survival effect on hematopoietic progenitors equipotent to that of SCF. ARP was further found to promote megakaryocytopoiesis and myelopoiesis and to potentiate the hematopoietic effects of early-acting cytokines and SCF ex vivo. Further studies will be required to define the ARP domains that are necessary and sufficient for these growth-related activities.

\section{SCF-ARP Similarities Predict Mutual Processes}

ARP replaced SCF in long-term cultures and supported the formation of floating "hematons," indicating the preserved pluripotential nature of the CD $34^{1}$ cells. Thus, ARP may be useful in conjunction with early-acting cytokines for the ex vivo expansion of hematopoietic cells, which may be beneficial in bone marrow transplantation (59). The antisense inhibition of $\mathrm{CD} 34^{1}$ proliferation by selective disabling of AChE-R mRNA suggests that SCF requires AChE- $R$ to drive cell proliferation. The molecular basis for the selective action of low concentrations of antisense oligonucleotides on AChE-R mRNA is likely attributable to intrinsic differences in the stability of this splicing variant (as suggested by its long, G,C-rich 3' untranslated region), and feedback regulation of the gene under antisense suppression (60). In any case, the complete rescue achieved with ARP proved that the short ARP and not the entire AChE-R protein is sufficient to support the proliferative effect of SCF. Several cytokine receptors (e.g., GM-CSF) mediate signals through cascades involving Janus and Srcrelated tyrosine kinases (61). Such kinases activate and phosphorylate tyrosine residues in their intracellular target proteins, including signal transducers and transcription factors (e.g., stat) (41). Therefore, ARP-induced potentiation of early-acting cytokine activities, in conjugation with the presence of a Stat-5 binding site in the ACHE promoter, suggests that ARP may autoregulate its levels. This, or similar mechanism(s), may explain both the prolonged effect of ARP on cultured CD $34^{1}$ progenitors, its accumulation in the blood of stressed mice, and its pronounced in vivo effect on AChE mRNA levels in bone marrow stem cells. The high sensitivity of AChE-R mRNA to low levels of AS 1 may be due to its 1094 bp 3'-untranslated region (UTR), with $62 \%$ G,C content. This marks it as being more vulnerable to nucleolytic degradation (62) than AChE-S mRNA, which includes a considerably shorter, 219-bp UTR with $66 \%$ G,C.

\section{ARP Potentiates In Vivo Hematopoietic Stress Responses}

The in vivo accumulation of ARP in mice following forced swim raises the possibility that the reported increased risk for brain infarcts following acute stress, exposure to anticholinesterases $(63,64)$, and Alzheimer's disease $(65,66)$ is associated with increased platelet counts due to AChE-R overproduction. Similarly, the increased risk for leukemias in farmers exposed to agricultural insecticides (67) may be related to AChE-R/ARP overproduction under chronic or repeated cholinesterase blockade. Anti-ARP antibodies provide a novel diagnostic tool for testing this option (and possibly for risk assessment) and antisense treatment may offer an attractive protocol for prevention of such adverse responses.

The mechanism(s) of ARP action on hematopoietic progenitors is unknown. However, there is evidence for cross-talk between hematopoietic cells at different stages of differentiation and bone marrow stromal or endothelial cells. Stroma influences cytokine production and is responsible for maintaining steady-state hematopoiesis and its adjustment under stress (52). It has been proposed that primitive $\mathrm{CD} 34^{1}$ progenitors provide a soluble positive feedback signal to induce cytokine production (53) and it is therefore tempting to speculate that ARP may play such a role. If so, the discovery of ARP would carry important implications for ex vivo stem cell expansion, cancer treatment, and gene therapy. Experiments to determine the cellular and molecular sites of action of ARP are currently underway.

\section{AChE-R/ARP as Ubiquitous Growth-Promoting Factors}

The stem cell survival and proliferative effects of ARP denote a previously unforeseen activity that is particular to the AChE-R protein yet distinct from the ACh hydrolysis and adhesion properties characteristic of the core domain common to all AChE isoforms. Thus, the significance of ARP may extend beyond the hematopoietic system. For example, the multi-organ expression AChE-R predicts roles for ARP during embryogenesis and may explain at least some of the elusive developmental function(s) of AChE. In the mammalian brain, ARP may affect the stress-associated plasticity of neuronal and glial properties, perhaps explaining the morphogenic activities of AChE-R in transfected glia (68). In the realm of applied biotechnology, it is important to note the significant recent advances in stem cell biology. For example, pluripotent stem cells can now be derived in vitro from cultured human primordial germ cells $(69,70)$. Moreover, neural stem cells were shown to produce a variety of blood cell types in vivo (71). Our current findings present ARP as a potential cue that may be involved in the induction of such growth and expansion capacities of pluripotent stem cells from multi-tissue origins. If so, the unique properties of this peptide can contribute toward the development of diverse human differentiating cell sources for biomedical and research purposes. 


\section{Acknowledgments}

The authors are grateful to Dr. Haim Gilon (Jerusalem) for preliminary peptide synthesis, to Drs. David Glick and Shlomo Seidman (Jerusalem) and to Dr. Roger Kornberg (Palo Alto) for reviewing this manuscript, and to Ms. Shoshana Baron for her assistance. Support was by the U.S.-Israel Binational Science Foundation (to H.S.) and the B. Adler Fund, the Israel Ministry of Health (to V.D.). D.G. was the incumbent of a research fellowship from the Tel-Aviv Sourasky Medical Center and of a Meirbaum Award, from Tel-Aviv University.

\section{References}

1. Jern C, Manhem K, Eriksson E, et al. (1991) Hemostatic responses to mental stress during the menstrual cycle. Thromb. Haemost. 66: 614-618.

2. Sutor AH. (1995) Thrombocytosis in childhood. Semin. Thromb. Hemost. 21: 330-339.

3. McEwen BS. (1998) Protective and damaging effects of stress mediators. N. Engl. J. Med. 338: 171-179.

4. Dygai AM, Shakhov VP, Mikhlenko AV, Goldberg ED. (1991) Role of glucocorticoids in the regulation of bone marrow hemopoiesis in stress reaction. Biomed. Pharmacother. 45: 9-14.

5. Maruyama S, Minagawa M, Shimizu T, et al. (1999) Administration of glucocorticoids markedly increases the numbers of granulocytes and extrathymic $\mathrm{T}$ cells in the bone marrow. Cell Immunol. 194: 28-35.

6. Lansdorp PM. (1995) Telomere length and proliferation potential of hematopoietic stem cells. J. Cell Sci. 108: 1-6.

7. Burdach S. (1991) The granulocyte/macrophage-colony stimulating factor (GM-CSF): Basic science and clinical application. Klin. Padiatr. 203: 302-310.

8. Lord KA, Abdollahi A, Hoffman-Liebermann B, Liebermann DA. (1993) Proto-oncogenes of the fos/jun family of transcription factors are positive regulators of myeloid differentiation. Mol. Cell Biol. 13: 841-851.

9. Dieterlen-Lievre F, Godin I, Pardanaud L. (1997) Where do hematopoietic stem cells come from? Int. Arch. Allergy Immunol. 112: 3-8.

10. Keller G, Snodgrass R. (1990) Life span of multipotential hematopoietic stem cells in vivo. J. Exp. Med. 171: 1407-1418.

11. Kaushansky K. (1998) Thrombopoietin and the hematopoietic stem cell. Blood 92: 1-3.

12. Metcalf D. (1993) The cellular basis for enhancement interactions between stem cell factor and the colony stimulating factors. Stem Cells (Dayt) 11(Suppl 2): 1-11.

13. Matthews W, Jordan CT, Gavin M, et al. (1991) A receptor tyrosine kinase cDNA isolated from a population of enriched primitive hematopoietic cells and exhibiting close genetic linkage to c- kit. Proc. Natl. Acad. Sci. U.S.A. 88: 9026-9030.

14. Small D, Levenstein M, Kim E, et al. (1994) STK-1, the human homolog of Flk-2/Flt-3, is selectively expressed in $\mathrm{CD} 34^{1}$ human bone marrow cells and is involved in the proliferation of early progenitor/stem cells. Proc. Natl. Acad. Sci. U.S.A. 91: 459-463.

15. Li CL, Johnson GR. (1994) Stem cell factor enhances the survival but not the self-renewal of murine hematopoietic longterm repopulating cells. Blood 84: 408-414.

16. Jacobsen SE, Okkenhaug C, Myklebust J, Veiby OP, Lyman SD. (1995) The FLT3 ligand potently and directly stimulates the growth and expansion of primitive murine bone marrow progenitor cells in vitro: synergistic interactions with interleukin (IL) 11, IL-12, and other hematopoietic growth factors. J. Exp. Med. 181: 1357-1363.

17. McNiece IK, Langley KE, Zsebo KM. (1991) Recombinant human stem cell factor synergises with GM-CSF, G-CSF,
IL-3 and epo to stimulate human progenitor cells of the myeloid and erythroid lineages. Exp. Hematol. 19: 226-231.

18. Bernstein ID, Andrews RG, Zsebo KM. (1991) Recombinant human stem cell factor enhances the formation of colonies by CD $34^{1}$ and CD $34^{1}$ lin- cells, and the generation of colonyforming cell progeny from CD $34^{1}$ lin- cells cultured with interleukin-3, granulocyte colony-stimulating factor, or granulocyte-macrophage colony-stimulating factor. Blood 77: 23162321.

19. Goldberg ED, Dygai AM, Zakharova O, Shakhov VP. (1990) The modulating influence of enkephalins on the bone marrow haemopoiesis in stress. Folia Biol. 36: 319-331.

20. Karpel R, Ben Aziz-Aloya R, Sternfeld M, et al. (1994) Expression of three alternative acetylcholinesterase messenger RNAs in human tumor cell lines of different tissue origins. Exp. Cell Res. 210: 268-277.

21. Massoulie J, Pezzementi L, Bon S, Krejci E, Vallette FM. (1993) Molecular and cellular biology of cholinesterases. Prog. Neurobiol. 41: 31-91.

22. Lev-Lehman E, Deutsch V, Eldor A, Soreq H. (1997) Immature human megakaryocytes produce nuclear-associated acetylcholinesterase. Blood 89: 3644-3653.

23. Grisaru D, Lev-Lehman E, Shapira M, et al. (1999) Human osteogenesis involves differentiation-dependent increases in the morphogenically active $3^{\prime}$ alternative splicing variant of acetylcholinesterase. Mol. Cell Biol. 19: 788-795.

24. Majumdar MK, Thiede MA, Mosca JD, Moorman M, Gerson SL. (1998) Phenotypic and functional comparison of cultures of marrow-derived mesenchymal stem cells (MSCs) and stromal cells. J. Cell Physiol. 176: 57-66.

25. Burstein SA, Adamson JW, Harker LA. (1980) Megakaryocytopoiesis in culture: Modulation by cholinergic mechanisms. J. Cell Physiol. 54: 201-208.

26. Paoletti F, Mocali A, Vannucchi AM. (1992) Acetylcholinesterase in murine erythroleukemia (Friend) cells: Evidence for megakaryocyte-like expression and potential growth-regulatory role of enzyme activity. Blood 79: 28732879.

27. Seidman S, Sternfeld M, Ben Aziz-Aloya R, et al. (1995) Synaptic and epidermal accumulations of human acetylcholinesterase are encoded by alternative 3'-terminal exons. Mol. Cell Biol. 15: 2993-3002.

28. Kaufer D, Friedman A, Seidman S, Soreq H. (1998) Acute stress facilitates long-lasting changes in cholinergic gene expression. Nature 393: 373-377.

29. Shohami E, Kaufer D, Chen Y, et al. (2000) Antisense prevention of neuronal damages following head injury in mice. J. Mol. Med. 78: 228-236.

30. Sternfeld M, Shoham S, Klein O, et al. (2000) Excess "readthrough" acetylcholinesterase attenuates but the "synaptic" variant intensifies neurodeterioration correlates. Proc. Natl. Acad. Sci. U.S.A. 97: 8647-8652.

31. Grisaru D, Deutsch V, Pick M, et al. (1999) Placing the newborn on the maternal abdomen after delivery increases the volume and CD34 cell content in the umbilical cord blood collected: An old maneuver with new applications. Am. J. Obstet. Gynecol. 180: 1240-1243.

32. Bertolini F, Battaglia M, Pedrazzoli P, et al. (1997) Megakaryocytic progenitors can be generated ex vivo and safely administered to autologous peripheral blood progenitor cell transplant recipients. Blood 89: 2679-2688.

33. Pick M, Nagler A, Grisaru D, Eldor A, Deutsch V. (1998) Expansion of megakaryocyte progenitors from human umbilical cord blood using a new two-step separation procedure. Br. J. Haematol. 103: 639-650.

34. Deutsch VR, Eldor A, Olson T, et al. (1996) Stem cell factor (SCF) synergizes with megakaryocyte colony stimulating activity in post-irradiated aplastic plasma in stimulating human megakaryocytopoiesis. Med. Oncol. 13: 31-42.

35. Piacibello W, Sanavio F, Garetto L, et al. (1998) Differential growth factor requirement of primitive cord blood hematopoietic stem cell for self-renewal and amplification vs proliferation and differentiation. Leukemia 12: 718-727. 
36. Raina AK, Menn JJ. (1993) Pheromone biosynthesis activating neuropeptide: From discovery to current status. Arch. Insect Biochem. Physiol. 22: 141-151.

37. Grifman M, Soreq H. (1997) Differentiation intensifies the susceptibility of pheochromocytoma cells to antisense oligodeoxynucleotide-dependent suppression of acetylcholinesterase activity. Antisense Nucleic Acid Drug Dev. 7: 351359.

38. Deutsch VR, Olson TA, Nagler A, et al. (1995) The response of cord blood megakaryocyte progenitors to IL-3, IL-6 and aplastic canine serum varies with gestational age. $B r . J$. Haematol. 89: 8-16.

39. Kaufer D, Soreq H. (1999) Tracking cholinergic pathways from psychological and chemical stressors to variable neurodeterioration paradigms. Curr. Opin. Neurol. 12: 739-743.

40. Shapira M, Tur-Kaspa I, Bosgraaf L, et al. (2000) A transcription-activating polymorphism in the ACHE promoter associated with acute sensitivity to anti-acetylcholinesterases. Hum. Mol. Genet. 9: 1273-1281.

41. Darnell JE Jr, Kerr IM, Stark GR. (1994) Jak-STAT pathways and transcriptional activation in response to IFNs and other extracellular signaling proteins. Science 264: 11415-11421.

42. McMahon A, Sabban EL. (1992) Regulation of expression of dopamine beta-hydroxylase in PC 12 cells by glucocorticoids and cyclic AMP analogues. J. Neurochem. 59: 2040-2047.

43. Tronche F, Kellendonk C, Kretz O, et al. (1999) Disruption of the glucocorticoid receptor gene in the nervous system results in reduced anxiety. Nat. Genet. 23: 99-103.

44. Cella N, Groner B, Hynes NE. (1998) Characterization of Stat5a and Stat5b homodimers and heterodimers and their association with the glucocortiocoid receptor in mammary cells. Mol. Cell Biol. 18: 1783-1792.

45. De Vroede M, Beukering R, Spit M, Jansen M. (1998) Rectal hydrocortisone during stress in patients with adrenal insufficiency. Arch. Dis. Child. 78: 544-547.

46. Blazsek I, Liu XH, Anjo A, et al. (1995) The hematon, a morphogenetic functional complex in mammalian bone marrow, involves erythroblastic islands and granulocytic cobblestones. Exp. Hematol. 23: 309-319.

47. Ross ME, Evinger MJ, Hyman SE, et al. (1990) Identification of a functional glucocorticoid response element in the phenylethanolamine $N$-methyltransferase promoter using fusion genes introduced into chromaffin cells in primary culture. J. Neurosci. 10: 520-530.

48. Lopez AJ. (1998) Alternative splicing of pre-mRNA: developmental consequences and mechanisms of regulation. Annu. Rev. Genet. 32: 279-305.

49. Xie J, McCobb DP. (1998) Control of alternative splicing of potassium channels by stress hormones. Science 280: 443446.

50. Chan RY, Adatia FA, Krupa AM, Jasmin BJ. (1998) Increased expression of acetylcholinesterase $\mathrm{T}$ and $\mathrm{R}$ transcripts during hematopoietic differentiation is accompanied by parallel elevations in the levels of their respective molecular forms. $J$. Biol. Chem. 273: 9727-9733.

51. Tarasenko LM, Grebennikova VF, Tarasenko VV, et al. (1992) The proteinase and alpha 1-antitrypsin activities in the tissues during emotional stress in rabbits. Fiziol. Zh. 38: 115117.

52. Gupta P, Blazar BR, Gupta K, Verfaillie CM. (1998) Human CD $34^{1}$ bone marrow cells regulate stromal production of interleukin-6 and granulocyte colony-stimulating factor and increase the colony-stimulating activity of stroma. Blood 91: 3724-3733.

53. Jazwiec B, Solanilla A, Grosset C, et al. (1998) Endothelial cell support of hematopoiesis is differentially altered by IL-1 and glucocorticoids. Leukemia 12: 1210-1220.

54. Sussman JL, Harel M, Silman I. (1993) Three-dimensional structure of acetylcholinesterase and of its complexes with anticholinesterase drugs. Chem. Biol. Interact. 87: 187-197.

55. Satoh T, Aramini JM, Li S, et al. (1997) Bioactive peptide design based on protein surface epitopes. A cyclic heptapeptide mimics CD4 domain $1 \mathrm{CC}^{\prime}$ loop and inhibits CD4 biological function. J. Biol. Chem. 272: 12175-12180.

56. Livnah O, Stura EA, Johnson DL, et al. (1996) Functional mimicry of a protein hormone by a peptide agonist: the EPO receptor complex at $2.8 \mathrm{~A}$. Science 273: 464-471.

57. Johnson DL, Farrell FX, Barbone FP, et al. (1998) Identification of a 13 amino acid peptide mimetic of erythropoietin and description of amino acids critical for the mimetic activity of EMP1. Biochemistry 37: 7699-7710.

58. Cwirla SE, Balasubramanian P, Duffin DJ, et al. (1997) Peptide agonist of the thrombopoietin receptor as potent as the natural cytokine. Science 276: 1696-1699.

59. Conrad PD, Emerson SG. (1998) Ex vivo expansion of hematopoietic cells from umbilical cord blood for clinical transplantation. J. Leukoc. Biol. 64: 147-155.

60. Galyam N, Grisaru D, Melamed-Book N, Grifman M, Eckstein F, Eldor A, Soreq H. (2001) Complex host cell responses to antisense suppression of ACHE gene expression. Antisense and Nucleic Acid Drug Development in press.

61. Taniguchi T. (1995) Cytokine signaling through nonreceptor protein tyrosine kinases. Science 268: 251-255.

62. Jacobson A, Peltz SW. (1996) Interrelationships of the pathways of mRNA decay and translation in eukaryotic cells. Annu. Rev. Biochem. 65: 693-739.

63. Schultz JA, Hoffman WE, Albrecht RF. (1993) Sympathetic stimulation with physostigmine worsens outcome from incomplete brain ischemia in rats. Anesthesiology 79: 114-121.

64. Harmsen P, Rosengren A, Tsipogianni A, Wilhelmsen L. (1990) Risk factors for stroke in middle-aged men in Goteborg, Sweden. Stroke 21: 223-229.

65. Inestrosa NC, Alarcon R, Arriagada J, Donoso A, Alvarez J. (1993) Platelets of Alzheimer patients: Increased counts and subnormal uptake and accumulation of [14C]5hydroxytryptamine. Neurosci. Lett. 163: 8-10.

66. Snowdon DA, Greiner LH, Mortimer JA, et al. (1997) Brain infarction and the clinical expression of Alzheimer disease. The Nun Study. JAMA 277: 813-817.

67. Brown LM, Blair A, Gibson R, et al. (1990) Pesticide exposure and other agricultural risk factors for leukemia among men in Iowa and Minnesota. Cancer Res. 50: 6585-6591.

68. Karpel R, Sternfeld M, Ginzberg D, et al. (1996) Overexpression of alternative human acetylcholinesterase forms modulates process extensions in cultured glioma cells. J. Neurochem. 66: 114-123.

69. Solter D, Gearhart J. (1999) Putting stem cells to work. Science 283: $1468-1470$.

70. Shamblott MJ, Axelman J, Wang S, et al. (1998) Derivation of pluripotent stem cells from cultured human primordial germ cells. Proc. Natl. Acad. Sci. U.S.A. 95: 13726-13731.

71. Bjornson CR, Rietze RL, Reynolds BA, Magli MC, Vescovi AL. (1999) Turning brain into blood: a hematopoietic fate adopted by adult neural stem cells in vivo. Science 283: 534-537. 